\title{
The closure of Sugen
}

\section{To the editor:}

I read with great interest the News story in the July issue (Nat. Biotechnol. 21, 722-723, 2003) on the closure of Sugen (S. San Francisco, CA, USA) in the wake of its takeover by Pfizer (New York, NY, USA). I was rather perplexed, however, to read the statement by Tony Hunter that Sugen was "a model of how to run a company." Rather, the reverse is true, and this was the reason for the company's downfall.

Sugen was founded by the eminent scientists Joseph Schlessinger (the ' $S$ ' in Sugen) and Axel Ullrich (the ' $U$ ' in Sugen). I was recruited as Vice President of Research in December 1992 and joined the company in 1993.

The portfolio of tyrphostins that was initiated, and continues to be developed, in Jerusalem by my group was licensed to Sugen by the Hebrew University of Jerusalem, Israel. The Hebrew University also helped the company to go public by stating that it would continue to collaborate over the development of these compounds. The agreement between the Hebrew University and Sugen to develop jointly novel kinase inhibitors was never fulfilled, and members of my research group in Israel were prevented from even talking to Sugen chemists. I was screened from the chemistry efforts across the hall, although the Sugen chemists were pursuing our joint ideas. All this took place while I served as Vice President of Research.

To cap it all, in 1999—-long after I resigned from the company-the Hebrew University's patent lawyers discovered that Sugen had submitted a patent application on plateletderived growth factor receptor kinase inhibitors made by Aviv Gazit and myself in 1997 in Jerusalem, independently of Sugen chemists, without even putting our names on the application! The application was of course withdrawn after some 'interesting' email exchanges between South San

Francisco and Jerusalem.

Another example of 'model' management was the way Sugen handled its collaboration with Amgen (Thousand Oaks, CA, USA). The projects financed by Amgen were not making progress, according to my judgment, and I therefore suggested some changes. These were submitted to the CEO but never discussed. The outcome of my comments was my removal from the joint Amgen-Sugen meetings! Amgen indeed pulled out about a year later, which did not surprise me. This should have been taken as a setback for Sugen, but its CEO turned a blind eye.

Sugen rejected the opportunity to develop novel Bcr-Abl kinase inhibitors, which we in Jerusalem had patented and published between 1991 and 1993. Sugen decided not to develop these novel Bcr-Abl kinase inhibitors as treatments for chronic myeloid leukemia "because there are not enough patients." The argument that this was the best system to demonstrate the proof of principle of signal transduction therapy, and that such a proof would bring Sugen money, did not wash. In 1996, Brian Druker and Nick Lydon of Novartis (Basel, Switzerland) convinced their company to develop Gleevec. (These authors graciously credit the Jerusalem team as the pioneers in their seminal paper of 1996; see ref. 1.) The rest is history.

A similar unfortunate approach was taken by Sugen in regard to the development of novel Jak-2 inhibitors, also licensed to Sugen by the Hebrew University. These inhibitors were based on studies we conducted with Chaim Roifman from the Hospital for Sick Children in Toronto, Canada. Our publication ${ }^{2}$ on the first Jak-2 pathway inhibitor and its utilization was delayed for almost two years, to allow Sugen to 'ponder' whether Jak-2 was a good target for leukemia treatment. The project was terminated before it even started, again because the patient population was considered too small! Sugen's management believed that the important targets were colon cancer, lung cancer, breast cancer and prostate cancer, and that finding treatments for these would bring the company billions.

I quickly realized that my Hebrew University group and I had no say in decisions taken in the company. I believed Sugen was heading downhill, so I left in 1994 and terminated our relationship entirely in 1997. I must add that I was not the only victim of these managerial 'skills' within the company.

Sugen is actually a model of how a company that ought to have been the pioneer in bringing signal transduction therapy to the patient bed failed because of poor management. It had excellent scientists and superb administrators, but it was bogged down by Byzantine intrigues. For the sake of the younger people who think that the world of start-up biotechnology is so rosy, I think it is important to add a note of caution.

\section{Alexander Levitzki}

Department of Biological Chemistry,

The Alexander Silberman Institute

of Life Sciences,

Hebrew University of Jerusalem, Jerusalem 91904, Israel

e-mail:levitzki@vms.huji.ac.il

1. Druker, B.J. et al. Nat. Med. 2, 561-566 (1996).

2. Meydan, N. et al. Nature 379, 645-648 (1996).

\section{Somatic cell nuclear transfer- how science outpaces the law}

\section{To the editor:}

Louis Guenin's Commentary from the May issue (Nat. Biotechnol. 21, 482-483) refers to 'the maze of enactments' of relevance to embryo research that have recently been passed by legislators. Because the benefits to society of embryo and stem cell research must be weighed against complex and shifting moral concerns, it is clear that laws often lag behind scientific advancement. We contend that this lag is leading to inflexible and illogical statutory responses that restrict embryonic stem (ES) cell research. This is likely to have an 